\title{
Probiotic potential of indigenous yeasts isolated during the fermentation of table olives from Northeast of Portugal
}

\author{
Tatiane Oliveira $^{\mathrm{a}, \mathrm{b}}$, Elsa Ramalhosa ${ }^{\mathrm{b}, *}$, Luís Nunes ${ }^{\mathrm{b}}$, José A. Pereira ${ }^{\mathrm{b}}$, Eliane Colla ${ }^{\mathrm{a}}$, \\ Ermelinda L. Pereira ${ }^{\mathrm{b}, *}$ \\ a Federal Technological University of Paraná, Câmpus Medianeira, 85884-000 Medianeira, Paraná, Brazil \\ ${ }^{\mathrm{b}}$ Mountain Research Centre (CIMO), School of Agriculture, Polytechnic Institute of Bragança, Campus de St ${ }^{g}$ Apolónia, $5300-253$ Bragança, Portugal
}

\section{A R T I C L E I N F O}

\section{Keywords:}

Antioxidant activity

Antimicrobial activity

Autoaggregation

In vitro digestive simulation

Table olives

Probiotics

\begin{abstract}
A B S T R A C T
The aim of this study was to evaluate the probiotic potential of 16 yeast strains previously isolated during the natural fermentation of table olives Negrinha de Freixo cultivar, in relation to enzymatic activities; ability to grow at $37^{\circ} \mathrm{C}$; antimicrobial activity; autoaggregation capacity; antioxidant activity and survival in gastrointestinal tract conditions. The highest antioxidant activity was observed for Saccharomyces cerevisiae, similar to the reference strain S. boulardii. Candida norvegica 7A and Galactomyces reessii 34A showed antifungal ability to the pathogenic microorganism Cryptococcus neoformans. Regarding the autoaggregation capacity, S. cerevisiae 15A, C. tropicalis $1 \mathrm{~A}$ and C. norvegica 7A showed $>80 \%$ after $24 \mathrm{~h}$. Pichia guilliermondii 25A and C. norvegica 7A were the most resistant to the simulated digestive conditions, similar to the reference strain ( $S$. boulardii). Thus, these results suggest that some yeast strains involved in the fermentation of table olives have probiotic potential. Industrial relevance: In this study, we highlight the probiotic potential of yeast microbiota usually found in green table olives. These yeast strains could be used as culture starters for the development of new functional products.
\end{abstract}

\section{Introduction}

Nowadays the search for a healthier lifestyle has led to the demand by consumers for healthy and natural products that could provide health benefits to the consumers. Accordingly, there has been a breakthrough in the development of so-called probiotics products. Probiotics are defined by the World Health Organization (WHO) as live microorganisms which when administered in adequate amounts confer a health benefit on the host (FAO/WHO, 2006). The term probiotic includes a wide variety of microorganisms, including bacteria and yeast (Perricone, Bevilacqua, Corbo, \& Sinigaglia, 2014). The microorganisms often used in probiotic preparations are mostly derived from human sources and/or animals, belonging to the genera Lactobacillus and Bifidobacterium and less frequently Enterococcus (Peres, Peres, HernándezMendoza, \& Malcata, 2012). The use of these bacteria has been confined almost exclusively to the production of fermented dairy products such as yogurts. However, the increasing number of lactose intolerance cases worldwide, together with the adverse effect of cholesterol content in dairy products (Argyri et al., 2013) and the increased market for vegetarian consumers, has led to the need of plant based probiotic strains that could be used without any restrictions (Rodríguez-Gómez, Romero-
Gil, García-García, Garrido-Fernández, \& Arroyo-López, 2014).

According to Ruiz-Moyano, Martín, Benito, Nevado, and Córdoba (2008), traditional fermented products can be a good basis for the development of functional foods of the probiotic type. Thus, the table olives obtained through the natural fermentation process by lactic acid bacteria (LAB) and yeast (natural flora) could be a promising probiotic that can be used as a functional starter culture or as a good source of probiotic microorganism (Argyri et al., 2013). Sourabh, Kanwar, and Sharma (2011) referred that species involved in the fermentation process could be used as protective or probiotic cultures as probiotics are relatively safe for human consumption and are designated as GRAS (Generally Recognized as Safe).

Nevertheless, in the last years the search for probiotic microorganisms from olives fermentation has focused on LAB (Argyri et al., 2013; Bautista-Gallego et al., 2013; Pessione, Bianco, Mangiapane, Cirrincione, \& Pessione, 2015; Rodríguez-Gómez et al., 2014). On the other hand, there are few studies on yeasts isolated from the fermentation of olives (Bautista-Gallego et al., 2011; Bonatsou, Benítez, Rodríguez-Gómez, Panagou, \& Arroyo-López, 2015; Silva et al., 2011). However, there is great interest in finding yeast strains with probiotic potential due to the numerous beneficial effects on human health,

\footnotetext{
* Corresponding authors.

E-mail addresses: tcgoliveira@outlook.com (T. Oliveira), elsa@ipb.pt (E. Ramalhosa), lfnunes@ipb.pt (L. Nunes), jpereira@ipb.pt (J.A. Pereira), ecolla@utfpr.edu.br (E. Colla), epereira@ipb.pt (E.L. Pereira).
} 
including prevention and treatment of intestinal diseases such as cholera (Vidon, Huchet, \& Rambaud, 1986). Other beneficial functions of yeasts are related with the improvement of bioavailability of minerals through the hydrolysis of phytate (Ragon et al., 2008), anti-inflammatory effects (Mumy, Chen, Kelly, \& McCormick, 2008) and detoxification of mycotoxins due to surface binding to the yeast cell wall (Moslehi-Jenabian, Pedersen, \& Jespersen, 2010). In addition, yeasts have the ability to produce natural antioxidants such as carotenoids, citric acid, ascorbic acid, tocopherols and glutathione that may retard the oxidative degeneration of lipids and improve the health of the host (Arroyo-López et al., 2012). Furthermore, Saccharomyces cerevisiae var. boulardii has been proven effective in several double-blind studies and preparations of this yeast have been sold as both a preventive and therapeutic agent (Lukaszewicz, 2012).

Thus, the aim of the present study was to evaluate the probiotic potential of 16 yeast strains isolated and identified on the natural fermentation process of table olives Negrinha de Freixo cultivar in relation to the enzymatic activity, ability to grow at $37^{\circ} \mathrm{C}$ (human body temperature), autoaggregation capacity, and antimicrobial and antioxidant activities, as well as the survival ability of the strains to the gastrointestinal (GI) transit. The results obtained will be important to promote the use of yeasts with probiotic potential in mixed starter cultures for table olives fermentation and other applications.

\section{Material and methods}

\subsection{Materials}

Sodium chloride, potassium dihydrogen phosphate, calcium chloride, potassium chloride, hydrogen peroxide, methanol, hydrochloric acid, disodium hydrogen phosphate, glucose, casein, pepsin, pancreatin and lysozyme were purchased from Panreac (Barcelona, Spain). Potato Dextrose broth, tryptone, yeast extract, agar and Mueller Hinton Agar (MHA) were obtained from Himedia (Kelton, USA). Tween 80 , erythromycin, penicillin $G$ and amphotericin $B$ were purchased from Liofilchem (Roseto degli Abruzzi, Italy). Xylan from beech wood and the radical 2,2-diphenyl-1-picryl-hydrazyl (DPPH) were obtained from Sigma Aldrich (St. Louis, USA). Arbutin was purchased from ChemCruz (Huissen, The Netherlands). Casein, phenol red and Brain Heart Infusion broth (BHI) were obtained from Merck (New Jersey, USA).

\subsection{Yeast strains}

A total of 16 yeast strains usually found in green table olives Negrinha de Freixo cv. were used in the present study, namely: Candida tropicalis 1A and 3A; Debaryomyces hansenii 8A; Galactomyces reessii 33A and 34A; Pichia guilliermondii 25A; Pichia manshurica 2A; Pichia membranifaciens 29A and 3B; Rhodotorula glutinis 27A; Rhodotorula graminis 20A; Saccharomyces cerevisiae 15A and 15B; Candida boidinii 32A and 37A; and Candida norvegica 7A. All of them were previously isolated and identified by Pereira, Ramalhosa, Borges, Pereira, and Baptista (2015) from olives in natura (before immersion in brine), olive pulp and brine during the spontaneous fermentation of table olives. The identification of the yeast strains was based on the sequencing of the internal transcribed spacer (ITS) region of the nuclear ribosomal DNA. Its sequences were deposited in NCBI (National Center for Biotechnology Information) GenBank data library, under accession numbers KM519627 to KM519637. Lyophilized Saccharomyces boulardii strain obtained from the drug Floratil ${ }^{\circledR}$ (Merck, New Jersey, USA) was used as a reference strain.

\subsection{Growth at $37^{\circ} \mathrm{C}$ and in vitro simulated gastric and pancreatic digestions}

A pre-inoculum of each strain was initially activated for $24 \mathrm{~h}$ in
Potato Dextrose Broth (PDB) at $25{ }^{\circ} \mathrm{C}$, for the study of yeasts' growth. At the end of the incubation period, the optical density (OD) of each culture was measured with the spectrophotometer (Cary 50 Scan), and an aliquot was added to $20 \mathrm{~mL}$ broth in order to adjust the OD of the suspension to 0.1 at a wavelength $(\lambda)$ of $600 \mathrm{~nm}$. Then, the cultures were incubated in a thermostated orbital shaker at two different temperatures ( 25 and $37^{\circ} \mathrm{C}$ ), with constant stirring (150 rpm), for $8 \mathrm{~h}$. The $\mathrm{OD}_{600}$ values were determined at hour intervals, in order to compare the kinetic growth at both temperatures.

In vitro gastric (GD) and pancreatic digestions (PD) were performed using the methodology described by Bonatsou et al. (2015). For the GD step, a synthetic gastric juice was prepared in a buffer solution at $\mathrm{pH}$ 2.0, containing $\mathrm{NaCl}(2.05 \mathrm{~g} / \mathrm{L}), \mathrm{KH}_{2} \mathrm{PO}_{4}(0.60 \mathrm{~g} / \mathrm{L}), \mathrm{CaCl}_{2}(0.11 \mathrm{~g} /$ L) and $\mathrm{KCl}(0.37 \mathrm{~g} / \mathrm{L})$, being the $\mathrm{pH}$ adjusted with $1 \mathrm{M} \mathrm{HCl}$. After medium's sterilization, pepsin $(0.0133 \mathrm{~g} / \mathrm{L})$ and lysozyme $(0.01 \mathrm{~g} / \mathrm{L})$ were added to obtain the gastric solution. The assayed yeast cultures were allowed to grow in PDB $\left(24 \mathrm{~h}\right.$ at $\left.25^{\circ} \mathrm{C}\right)$, centrifuged $(5000 \mathrm{~g}$, $10 \mathrm{~min}, 4^{\circ} \mathrm{C}$ ) and the pellet was washed twice with the buffer solution. Afterwards, the cells were re-suspended in the gastric solution, adjusted to an $\mathrm{OD}$ value equal to $0.5(\lambda=600 \mathrm{~nm})$ and incubated for $2.5 \mathrm{~h}$ at $37^{\circ} \mathrm{C}$, in the orbital shaker at $200 \mathrm{rpm}$ to simulate the peristaltic movements.

The PD simulation was carried out using a buffer solution at $\mathrm{pH}$ 8.0, adjusted with $1 \mathrm{M} \mathrm{HCl}$, formulated by bile salts $(3.0 \mathrm{~g} / \mathrm{L})$, pancreatin $(0.1 \mathrm{~g} / \mathrm{L}), \mathrm{Na}_{2} \mathrm{HPO}_{4}(26.9 \mathrm{~g} / \mathrm{L})$ and $\mathrm{NaCl}(8.5 \mathrm{~g} / \mathrm{L})$. Harvested cells from the previous GD step were centrifuged and washed twice in a sterile isotonic solution and re-suspended in the simulated pancreatic solution. After shaking the suspension ( $200 \mathrm{rpm}, 3.5 \mathrm{~h}$ at $37^{\circ} \mathrm{C}$ ), the pellet was washed and the cells were re-suspended in a volume of isotonic solution $(0.9 \% \mathrm{NaCl}, \mathrm{w} / \mathrm{v})$. The plating on PDA culture medium, at the beginning and end of each digestive simulation, were performed to assess cell viability. For each strain, four independent assays were performed.

\subsection{Enzymatic activity}

The enzymatic activity of the yeasts was done using qualitative tests. Strains were initially grown on PDA medium and then inoculated in an enzyme screening medium (except for the catalase test). Each test was carried out in three independent assays and the results were qualitatively expressed as: "-" (no activity); "+" (weak activity); “+ +" (moderate activity); and " +++ " (strong activity). For the catalase, results were expressed in terms of presence "P" or absence "0" of this activity.

Catalase activity of the yeasts was performed according to the method described by Whittenbury (1964), by adding 3\% (v/v) hydrogen peroxide onto the yeast colonies. Catalase activity was evidenced by the formation of bubbles.

Protease activity was determined by the method described by Strauss, Jolly, Lambrechts, and Rensburg (2001), by spreading yeast colonies onto PDA containing $20 \mathrm{~g} / \mathrm{L}$ casein. After the incubation period ( 5 days at $30{ }^{\circ} \mathrm{C}$ ), a positive result was considered when a clear zone around the colony was observed.

$\beta$-Glucosidase activity assays were performed according to the method described by Bautista-Gallego et al. (2011), using arbutin as substrate. $\beta$-Glucosidase activity was evidenced by the appearance of a dark brown colour around the colonies.

Lipase activity was performed according to the method described by Samad et al. (1989), with few modifications. The Yeast Extract Agar medium (YEA, tryptone $6.0 \mathrm{~g} / \mathrm{L}$, yeast extract $3.0 \mathrm{~g} / \mathrm{L}$ and agar $15 \mathrm{~g} / \mathrm{L}$ ), supplemented with Tween $80(1 \%)$ and phenol red $(0.01 \%, \mathrm{w} / \mathrm{v})$ at $\mathrm{pH}$ 7.3-7.4, was inoculated with different isolates of yeasts and incubated at $37^{\circ} \mathrm{C}$ for $48 \mathrm{~h}$. Lipase activity was observed by the colour change of the medium (red to yellow).

Amylase activity was performed using the medium starch agar. After incubation $\left(30^{\circ} \mathrm{C}\right.$ for 5 days), the plates were flooded with iodine solution and the appearance of a brown colour around a colony was 
considered a positive result.

The xylanase activity was determined according to the method described by Hernández, Martín, Aranda, Pérez-Nevado, and Córdoba (2007). The appearance of a clear halo around the colonies was considered a positive result.

\subsection{Antioxidant activity (2,2-diphenyl-1-picryl-hydrazyl (DPPH) free radical scavenging assay)}

The assessment of the scavenging ability of the 2,2-diphenyl-1-picryl-hydrazyl (DPPH) radical of each strain was performed in three independent assays, according to the method described by GilRodríguez, Carrascosa, and Requena (2015), with few modifications. Strains were allowed to grow at $37^{\circ} \mathrm{C}$ for $24 \mathrm{~h}$, being the $\mathrm{OD}_{600}$ adjusted to 1.20 , corresponding to a cell concentration on the order of 6-7 $\log \mathrm{CFU} / \mathrm{mL}$ and then centrifuged $\left(7200 \mathrm{~g}, 10 \mathrm{~min}, 4^{\circ} \mathrm{C}\right)$. The resulting pellet was washed twice with a sterile solution $0.9 \% \mathrm{NaCl}(\mathrm{w} / \mathrm{v})$ and then re-suspended in $2 \mathrm{~mL}$ of the same solution. Each test sample (1.6 mL) was added to $2 \mathrm{~mL}$ of a DPPH methanolic solution $(0.2 \mathrm{mM})$. After shaking, the mix was incubated for $30 \mathrm{~min}$, at room temperature, in darkness. The scavenging capacity of DPPH free radicals was measured by spectrophotometry (Cary $50 \mathrm{Scan}$ ) at $\lambda=517 \mathrm{~nm}$. An aliquot containing $1.6 \mathrm{~mL}$ of $0.9 \% \mathrm{NaCl}(\mathrm{w} / \mathrm{v})$ and $2 \mathrm{~mL}$ of DPPH methanolic solution, which was also incubated for $30 \mathrm{~min}$ in the dark, was used as blank. The percentage of antioxidant activity (A.A) was calculated as follows:

$\%$ A. A. $=\left[1-\left(\mathrm{A}_{517 \text { (Sample) }} / \mathrm{A}_{517 \text { (Blank) })}\right)\right] \times 100$

\subsection{Autoaggregation capacity}

The autoaggregation percentage of strains was performed using the method described by Gil-Rodríguez et al. (2015). Sample (1.2 mL) of yeast culture in PDB broth was harvested by centrifugation $(7200 g$, $5 \mathrm{~min}, 4^{\circ} \mathrm{C}$ ) and washed twice with a sterile solution $0.9 \% \mathrm{NaCl}(\mathrm{w} / \mathrm{v})$. The suspension obtained was re-suspended in $1 \mathrm{~mL}$ of the same solution $(0.9 \% \mathrm{NaCl}, \mathrm{w} / \mathrm{v})$ and transferred to a disposable plastic cuvette. Without shaking the yeast suspension, the absorbance at $600 \mathrm{~nm}$ was measured at the beginning $\left(\mathrm{A}_{0}\right)$ and 2,4 and $24 \mathrm{~h}\left(\mathrm{~A}_{\mathrm{T}}\right)$ after that. The autoaggregation percentage was calculated as follows:

\%Autoaggregation $=\left[1-\left(\mathrm{A}_{\mathrm{T}} / \mathrm{A}_{0}\right)\right] \times 100$

For each strain, three independent assays were performed.

\subsection{Antimicrobial activity}

All strains were tested in triplicate (independent assays) for antimicrobial activity in the presence of two yeasts (Candida albicans and Cryptococcus neoformans) and three bacteria (Pseudomonas aeruginosa, Escherichia coli and Staphylococcus aureus) by the agar diffusion method. These pathogenic microorganisms belong to the collection of the School of Agriculture of the Polytechnic Institute of Bragança. The cultures of these microorganisms were inoculated into $5 \mathrm{~mL}$ of Brain Heart Infusion broth (BHI) and incubated at $25^{\circ} \mathrm{C}$ (yeast) and $37{ }^{\circ} \mathrm{C}$ (bacteria) for $16-18 \mathrm{~h}$. Subsequently, the suspensions were diluted into sterile saline $(0.9 \% \mathrm{NaCl}, \mathrm{w} / \mathrm{v})$ to obtain a suspension with a turbidity corresponding to $0.5 \mathrm{McF}$ arland standard (8-9 $\log \mathrm{cfu} / \mathrm{mL}$ ) and seeded using a sterile swab on the surface of the culture medium (Mueller Hinton Agar (MHA)) for bacteria and MHA with $2 \%$ glucose (w/v) for yeast. Once dried, $10 \mu \mathrm{L}$ of each suspension of the assayed yeasts were inoculated in paper discs (6.0 $\mathrm{mm}$ in diameter, Oxoid), previously placed on the surface of the medium. Antibacterial antibiotics, erythromycin $(15 \mu \mathrm{g})$ and penicillin $\mathrm{G}(10 \mathrm{IU})$, discs and the antifungal amphotericin B $(20 \mu \mathrm{g})$ were used as positive controls. BHI broth at pH 6.5 was used as negative control. The plates were incubated at $37^{\circ} \mathrm{C}$ (bacteria) and $25{ }^{\circ} \mathrm{C}$ (yeast) during $2-5$ days. The results were determined from the appearance of a clear halo around the filter paper discs.

\subsection{Statistical analysis}

Statistical analysis of the antioxidant activity, autoaggregation and in vitro simulated gastric and pancreatic digestions, was carried out by One-Way Analysis of Variance, being the means compared by the Tukey's test, using SPSS v.20 software (SPSS Inc., Chicago, USA). For determining the specific growth rate $(\mu)$ for each of the isolates, a linear regression analysis was carried out using Excel of Microsoft Corporation (2013) and using the values from the natural log of the optical density (LN OD) versus time, comprised in the exponential growth phase.

In order to identify the yeast strains with desirable probiotic properties, Principal Component Analysis (PCA) was applied in the program SPSS (v. 20.0). The results of the qualitative tests (enzyme activity) were converted into four qualitative codes (1 - none; 2 - low, 3 moderate, 4 - strong activity). For the selection of the number of Principal Components or Factors, the Kaiser criterion test was applied and only factors with eigen-values higher than 1.00 were maintained.

\section{Results and discussion}

\subsection{Growth $a 37^{\circ} \mathrm{C}$ and in vitro simulated gastric and pancreatic digestions}

The assessment of the ability of yeast growth at $37^{\circ} \mathrm{C}$ is an important parameter when it is desired to select promising probiotic microorganisms (Gil-Rodríguez et al., 2015). To exert their beneficial effects, microorganisms need to multiply within the host. In this study, the strains that showed the highest specific growth rate $(\mu)$ at $37^{\circ} \mathrm{C}$ (data no shown) were $S$. cerevisiae $15 \mathrm{~B}\left(\mu=0.718 \mathrm{~h}^{-1}\right)$, C. tropicalis $1 \mathrm{~A}$ $\left(\mu=0.678 \mathrm{~h}^{-1}\right)$ and P. membranifaciens 29A $\left(\mu=0.676 \mathrm{~h}^{-1}\right)$, similar to the probiotic reference $S$. boulardii $\left(\mu=0.584 \mathrm{~h}^{-1}\right)$. These results showed that this temperature was favorable for their growth and, therefore, these strains can easily adapt to the temperature of the host. Similar results were also obtained by Gil-Rodríguez et al. (2015) for $S$. cerevisiae IFI-1145 and P. membranifaciens IFI-946, isolated from food and beverages. In contrast, isolates belonging to the genus Rhodotorula, $R$. graminis $20 \mathrm{~A}$ and $R$. glutinis $27 \mathrm{~A}$, showed lower growth rates at $37^{\circ} \mathrm{C}$ $\left(0.109 \mathrm{~h}^{-1}\right.$ and $0.186 \mathrm{~h}^{-1}$, respectively) than at $25^{\circ} \mathrm{C}$, suggesting growing difficulties at human body temperature. Thus, in our study, only 9 strains of the 16 initially tested strains showed good ability to survive at $37^{\circ} \mathrm{C}$, being afterwards subjected to in vitro GD and PD simulation assays, together with $S$. boulardii (reference strain).

Table 1 shows the results of the survival percentage of all tested strains, as well as the probiotic yeast, $S$. boulardii, as reference strain. All strains were resistant to GD process, indicating C. tropicalis $3 \mathrm{~A}$ and $P$. guilliermondii 25A had significantly $(p<0.05)$ higher survival rates than the other strains, including the reference strain. The survival rates to GD of $C$. tropicalis $3 \mathrm{~A}$ and $P$. guilliermondii $25 \mathrm{~A}$ were equal to $194.76 \pm 26.52 \%$ and $179.43 \pm 25.00 \%$, respectively. These results indicate that these microorganisms are not affected by the environmental conditions of the stomach, as their population almost doubled. The remaining strains showed survival rates ranging between $72.65 \pm 40.55 \%$ (C. tropicalis $1 \mathrm{~A})$ and $3.16 \pm 1.71 \%$ (S. cerevisiae $15 \mathrm{~A}$ ); however, there was high variability for the same sample, resulting in high standard deviations. Therefore, no significant differences between these samples and the reference strain (44.43 $\pm 1.93 \%)$ were observed. This variability was also stated by Bonatsou et al. (2015) in a study conducted with yeast isolated from Greek natural black table olives, particularly with $P$. guilliermondii (492.05 $\pm 319.63 \%)$.

After the period of exposure to GD conditions $(2.5 \mathrm{~h})$, the strains were then subjected to PD simulation for $3.5 \mathrm{~h}$. All strains survived to the synthetic pancreatic juice. $S$. cerevisiae $15 \mathrm{~B}$ showed a value $(175.98 \pm 47.84 \%)$ significantly higher $(p<0.05)$ than other strains, excluding the strain $C$. norvegica 7A $(125.75 \pm 47.24 \%)$. These strains increased their effective population, suggesting good adaptability to 
Table 1

Survival (\%) of the yeast strains to the gastric and pancreatic digestions and overall survival (mean \pm standard deviation, $\mathrm{n}=4$ ).

\begin{tabular}{|c|c|c|c|c|}
\hline Isolates & Species & Gastric digestion & Pancreatic digestion & Overall survival \\
\hline $1 \mathrm{~A}$ & C. tropicalis & $72.65 \pm 40.55^{\mathrm{b}}$ & $56.11 \pm 0.55^{\mathrm{b}, \mathrm{c}}$ & $9.05 \pm 6.40^{\mathrm{b}}$ \\
\hline $3 \mathrm{~A}$ & C. tropicalis & $194.76 \pm 26.52^{\mathrm{a}}$ & $61.41 \pm 30.59^{\mathrm{b}, \mathrm{c}}$ & $9.04 \pm 5.91^{\mathrm{b}}$ \\
\hline 15B & S. cerevisiae & $39.15 \pm 17.46^{\mathrm{b}, \mathrm{c}, \mathrm{d}}$ & $175.98 \pm 47.84^{\mathrm{a}}$ & $2.80 \pm 0.36^{b}$ \\
\hline $15 \mathrm{~A}$ & S. cerevisiae & $3.16 \pm 1.71^{\mathrm{d}}$ & $12.61 \pm 11.63^{\mathrm{c}}$ & $0.13 \pm 0.13^{\mathrm{b}}$ \\
\hline $7 \mathrm{~A}$ & C. norvegica & $49.75 \pm 13.72^{\mathrm{b}, \mathrm{c}}$ & $125.75 \pm 47.24^{\mathrm{a}, \mathrm{b}}$ & $14.52 \pm 3.32^{\mathrm{a}, \mathrm{b}}$ \\
\hline $8 \mathrm{~A}$ & D. hansenii & $40.71 \pm 2.03^{\mathrm{b}, \mathrm{c}, \mathrm{d}}$ & $97.74 \pm 5.58^{\mathrm{b}}$ & $7.38 \pm 3.63^{b}$ \\
\hline $37 \mathrm{~A}$ & C. boidinii & $16.16 \pm 5.62^{\mathrm{c}, \mathrm{d}}$ & $18.17 \pm 7.75^{\mathrm{c}}$ & $0.48 \pm 0.35^{\mathrm{b}}$ \\
\hline $25 \mathrm{~A}$ & P. guilliermondii & $179.43 \pm 25.00^{\mathrm{a}}$ & $68.91 \pm 22.59^{\mathrm{b}, \mathrm{c}}$ & $29.13 \pm 16.95^{\mathrm{a}}$ \\
\hline $2 \mathrm{~A}$ & P. manshurica & $29.63 \pm 7.46^{\mathrm{b}, \mathrm{c}, \mathrm{d}}$ & $11.05 \pm 6.09^{c}$ & $9.53 \pm 2.98^{\mathrm{a}, \mathrm{b}}$ \\
\hline $\mathrm{Sb}$ & S. boulardii & $44.43 \pm 1.93^{\mathrm{b}, \mathrm{c}, \mathrm{d}}$ & $99.79 \pm 34.11^{b}$ & $13.33 \pm 8.98^{\mathrm{a}, \mathrm{b}}$ \\
\hline
\end{tabular}

Different letters in the same column indicate significant differences by Tukey's test $(p<0.05)$.

these environmental conditions. Silva et al. (2011) also demonstrated similar results for the yeasts isolated from Portuguese brine table olives to bile salts.

Regarding the overall survival of the simulation of both digestive processes (GD and PD), it was observed that the strain P. guilliermondii $25 \mathrm{~A}$ showed the greatest resistance to the entire digestive process, with a value of $29.13 \pm 16.95 \%$. This value was statistically similar to that of $S$. boulardii and the strains $C$. norvegica 7A $(14.52 \pm 3.32 \%)$ and $P$. manshurica $2 \mathrm{~A}(9.53 \pm 2.98 \%)$. C. boidinii $37 \mathrm{~A}$ and $S$. cerevisiae $15 \mathrm{~A}$ showed the lowest resistance, with rates of $0.48 \pm 0.35 \%$ and $0.13 \pm 0.13 \%$, respectively.

\subsection{Enzymatic activity}

Catalase activity was detected in all isolates. Similar results were also observed by Bautista-Gallego et al. (2011) and Hernández et al. (2007), in most yeasts isolated during fermentation of table olives. The ability of the yeast to produce this enzyme can be of great interest, since it is linked to the antioxidant capacity (Chen et al., 2010). In relation to lipase, C. tropicalis 3A, C. boidinii 32A and G. ressii 33A did not show any activity, while $P$. manshurica $2 \mathrm{~A}$ and $S$. cerevisiae $15 \mathrm{~A}$ and $15 \mathrm{~B}$ showed high activity. The protease and xylanase activities were quite weak or null in most of the isolates assayed; however, lipase and protease can promote the probiotic potential (Syal \& Vohra, 2013), since they contribute to the improvement of digestion of lipids and proteins in the gastrointestinal tract. Amylase is responsible for the hydrolysis of polysaccharides by facilitating the breakdown of starch and glycogen in the human diet, thus contributing to the digestive system (Motta, 2000). Nevertheless, only two strains (C. boidinii 32A and G. reessii 33A) showed activity of this enzyme. Regarding $\beta$-glucosidase, strong activity was detected in $R$. glutinis 27A and $R$. graminis 20A, while moderate activity was observed for $C$. norvegica 7A, $P$. guilliermondii 25A and $G$. reessii 33A. This enzyme affects the sensory characteristics of table olives, since $\beta$-glucosidase is involved in the biodegradation of polyphenols in fruit, reducing the oleuropein content, which is responsible for the bitterness of fruit (Arroyo-López et al., 2012).

\subsection{Antioxidant activity}

Table 2 shows the DPPH free radical scavenging activity for each yeast strain. The highest antioxidant activities were obtained for $S$. cerevisiae $15 \mathrm{~A}(16.47 \pm 3.44 \%)$ and $15 \mathrm{~B}(18.34 \pm 2.24 \%)$, similar to the reference strain $S$. boulardii $(16.22 \pm 3.50 \%)$, while the lowest values were obtained for $C$. boidinii $32 \mathrm{~A}(2.55 \pm 3.45 \%)$ and $37 \mathrm{~A}$ $(3.52 \pm 0.88 \%)$. Gil-Rodríguez et al. (2015), in a study with yeasts isolated from different food and beverages, obtained higher values for different strains of $S$. cerevisiae, ranging from $19.74 \pm 0.12 \%$ (IF-88) to $56.97 \pm 0.30 \%$ (IFI-279), using a similar method to the present work. It is believed that the antioxidant activity of yeast is mainly due to the high content of $(1,3)-\beta$-D-glucan and other $\beta$-glucans found in the cell wall (Abbas, 2006; Jaehrig, Rohn, Kroh, Fleischer, \& Kurz, 2007), to other cellular compounds and due to the presence of antioxidant enzymes such as superoxide dismutase, glutathione peroxidase and catalase (Chen et al., 2010).

\subsection{Autoaggregation capacity}

Probiotic microorganisms, beyond resisting the conditions of the human gastrointestinal tract, should have good adherence to epithelial cells to be able to colonize and thus exert its beneficial properties. The autoaggregation ability is reflected in the ability of microorganisms to join together, forming cellular aggregates, thereby favoring gastrointestinal colonization (García-Cayuela et al., 2014). This ability is an important prerequisite for the colonization of probiotic strain in gastrointestinal tract, preventing their immediate elimination by the peristaltic movements and allowing a competitive advantage among existing microorganisms (Syal \& Vohra, 2013).

The autoaggregation abilities of the assayed yeasts, determined at different time intervals, are presented in Table 2 . At $2 \mathrm{~h}$ of incubation at $37^{\circ} \mathrm{C}$, the strains exhibited high variability in autoaggregation percentages, ranging between $2.86 \pm 1.18 \%(R$. glutinis 27A) and $74.53 \pm 4.23 \%$ (C. tropicalis 1A). C. tropicalis showed autoaggregation percentage significantly higher $(p<0.05)$ than the other strains. Higher autoaggregation capacity of this strain was also reported by Syal and Vohra (2013), after $3 \mathrm{~h}$ of incubation (88.48 $\pm 0.33 \%$ ). After $4 \mathrm{~h}$ of incubation, the strains $S$. cerevisiae $15 \mathrm{~A}$ and $15 \mathrm{~B}, C$. norvegica $7 \mathrm{~A}, C$. boidinii $37 \mathrm{~A}$ and $P$. manshurica $2 \mathrm{~A}$, significantly increased their ability to form cellular aggregates, increasing continuously up to $24 \mathrm{~h}$. The highest percentages of autoaggregation were determined after $24 \mathrm{~h}$ of incubation and ranged from $20.11 \pm 4.20 \%$ ( $R$. graminis 20A) to $93.94 \pm 4.73 \%$ (C. tropicalis $1 \mathrm{~A})$. The variability in these results indicates that the autoaggregation ability is strongly strain dependent, as suggested by Gil-Rodríguez et al. (2015). Our autoaggregation results obtained at $24 \mathrm{~h}$ for $S$. cerevisiae $15 \mathrm{~A}$ and $15 \mathrm{~B}(91.71 \pm 5.58 \%$ and $74.33 \pm 6.93 \%$, respectively) were similar, under the same condition to those values reported by Gil-Rodríguez et al. (2015) for $S$. cerevisiae IFI-87 (83.3 \pm 0.1\%) and IFI-244 (99.8 $\pm 5.74 \%)$, isolated from food and beverages. Syal and Vohra (2013) reported values of $100 \%$ after $20 \mathrm{~h}$ of incubation for $P$. manshurica and $S$. cerevisiae species.

\subsection{Antimicrobial activity}

Among the yeast strains studied, only two strains (C. norvegica 7A and $G$. reessii 34A) showed antimicrobial activity against $C$. neoformans (data not shown). Indeed, the strains $G$. reessii 34A and $C$. norvegica 7A showed inhibition halos of 2.7 and $1.5 \mathrm{~cm}$, respectively. It should be noted that the antifungal agent used as a positive control (amphotericin B) showed a slightly lower inhibition halo $(2.2 \mathrm{~cm}$ diameter $)$ compared to the strain $G$. reessii 34A, suggesting that this strain has a strong antimicrobial activity against this microorganism. Antimicrobial activity 
Table 2

Antioxidant activity (\%) and autoaggregation capacity (\%) of the assayed yeasts strains after $2 \mathrm{~h}, 4 \mathrm{~h}$ and $24 \mathrm{~h}$ (mean \pm standard deviation, $\mathrm{n}=3$ ).

\begin{tabular}{|c|c|c|c|c|c|}
\hline \multirow[t]{2}{*}{ Isolates } & \multirow[t]{2}{*}{ Species } & \multirow[t]{2}{*}{ DPPH scavenging activity (\%) } & \multicolumn{3}{|l|}{ Autoaggregation (\%) } \\
\hline & & & $2 \mathrm{~h}$ & $4 \mathrm{~h}$ & $24 \mathrm{~h}$ \\
\hline $1 \mathrm{~A}$ & C. tropicalis & $8.48 \pm 2.16^{\mathrm{b}}$ & $74.53 \pm 4.23^{\mathrm{A}, \mathrm{a}}$ & $77.54 \pm 4.50^{\mathrm{A}, \mathrm{a}}$ & $93.94 \pm 4.73^{\mathrm{B}, \mathrm{a}}$ \\
\hline $3 \mathrm{~A}$ & C. tropicalis & $7.85 \pm 0.76^{\mathrm{b}}$ & $65.5 \pm 0.24^{\mathrm{A}, \mathrm{a}, \mathrm{b}}$ & $71.29 \pm 1.84^{\mathrm{A}, \mathrm{a}, \mathrm{b}}$ & $78.37 \pm 3.57^{\mathrm{B}, \mathrm{b}, \mathrm{c}}$ \\
\hline $29 \mathrm{~A}$ & P. membranifaciens & ND & $48.16 \pm 7.71^{\mathrm{A}, \mathrm{c}, \mathrm{d}}$ & $47.11 \pm 4.22^{\mathrm{A}, \mathrm{c}, \mathrm{d}}$ & $76.13 \pm 5.46^{\mathrm{B}, \mathrm{c}}$ \\
\hline 3B & P. membranifaciens & ND & $54.71 \pm 8.56^{\mathrm{A}, \mathrm{b}, \mathrm{c}}$ & $65.60 \pm 4.07^{\mathrm{A}, \mathrm{B}, \mathrm{a}, \mathrm{b}}$ & $77.08 \pm 1.70^{\mathrm{B}, \mathrm{c}}$ \\
\hline $15 B$ & S. cerevisiae & $18.34 \pm 2.24^{\mathrm{a}}$ & $53.73 \pm 6.67^{\mathrm{A}, \mathrm{b}, \mathrm{c}}$ & $71.23 \pm 3.78^{\mathrm{B}, \mathrm{a}, \mathrm{b}}$ & $74.33 \pm 6.93^{\mathrm{B}, \mathrm{c}}$ \\
\hline $15 \mathrm{~A}$ & S. cerevisiae & $16.47 \pm 3.44^{\mathrm{a}}$ & $59.97 \pm 3.09^{\mathrm{A}, \mathrm{b}}$ & $71.92 \pm 6.30^{\mathrm{B}, \mathrm{a}}$ & $91.71 \pm 5.58^{\mathrm{C}, \mathrm{a}, \mathrm{b}}$ \\
\hline $7 \mathrm{~A}$ & C. norvegica & $6.57 \pm 0.85^{\mathrm{b}}$ & $38.27 \pm 0.30^{\mathrm{A}, \mathrm{d}, \mathrm{e}}$ & $59.21 \pm 5.24^{\mathrm{B}, \mathrm{b}, \mathrm{c}}$ & $82.72 \pm 7.14^{\mathrm{C}, \mathrm{a}, \mathrm{b}, \mathrm{c}}$ \\
\hline $8 \mathrm{~A}$ & D. hansenii & $4.41 \pm 1.95^{\mathrm{b}}$ & $31.49 \pm 3.55^{\mathrm{A}, \mathrm{e}, \mathrm{f}}$ & $30.83 \pm 3.27^{\mathrm{A}, \mathrm{e}, \mathrm{f}}$ & $34.37 \pm 10.80^{\mathrm{A}, \mathrm{d}}$ \\
\hline $20 \mathrm{~A}$ & R. graminis & ND & $3.35 \pm 0.71^{\mathrm{A}, \mathrm{h}}$ & $4.05 \pm 1.42^{\mathrm{A}, \mathrm{h}}$ & $20.11 \pm 4.20^{\mathrm{B}, \mathrm{d}}$ \\
\hline $37 \mathrm{~A}$ & C. boidinii & $3.52 \pm 0.88^{\mathrm{b}}$ & $26.46 \pm 2.95^{\mathrm{A}, \mathrm{e}, \mathrm{f}}$ & $41.82 \pm 4.16^{\mathrm{B}, \mathrm{d}, \mathrm{e}}$ & $76.58 \pm 7.90^{\mathrm{C}, \mathrm{c}}$ \\
\hline $32 \mathrm{~A}$ & C. boidinii & $2.55 \pm 3.45^{\mathrm{b}}$ & $8.96 \pm 4.53^{\mathrm{A}, \mathrm{h}}$ & $13.58 \pm 6.40^{\mathrm{B}, g, \mathrm{~h}}$ & $25.36 \pm 3.69^{\mathrm{B}, \mathrm{d}}$ \\
\hline $25 \mathrm{~A}$ & P. guilliermondii & $7.92 \pm 2.15^{\mathrm{b}}$ & $25.05 \pm 5.13^{\mathrm{A}, \mathrm{e}, \mathrm{f}, \mathrm{g}}$ & $30.66 \pm 6.66^{\mathrm{A}, \mathrm{e}, \mathrm{f}}$ & $73.66 \pm 2.65^{\mathrm{B}, \mathrm{c}}$ \\
\hline 27A & R. glutinis & ND & $2.86 \pm 1.18^{\mathrm{A}, \mathrm{h}}$ & $5.12 \pm 1.88^{\mathrm{A}, \mathrm{h}}$ & $23.67 \pm 8.68^{\mathrm{B}, \mathrm{d}}$ \\
\hline $2 \mathrm{~A}$ & P. manshurica & ND & $12.82 \pm 2.00^{\mathrm{A}, \mathrm{g}, \mathrm{h}}$ & $24.75 \pm 5.05^{\mathrm{B}, \mathrm{f}, \mathrm{g}}$ & $76.86 \pm 1.46^{\mathrm{C}, \mathrm{c}}$ \\
\hline $33 \mathrm{~A}$ & G. reessii & $8.14 \pm 1.72^{\mathrm{b}}$ & $22.01 \pm 4.95^{\mathrm{A}, \mathrm{f}, \mathrm{g}}$ & $29.21 \pm 5.51^{\mathrm{A}, \mathrm{e}, \mathrm{f}}$ & $70.50 \pm 3.10^{\mathrm{B}, \mathrm{c}}$ \\
\hline $34 \mathrm{~A}$ & G. reessii & ND & $34.86 \pm 4.27^{\mathrm{A}, \mathrm{e}, \mathrm{f}}$ & $30.55 \pm 4.88^{\mathrm{A}, \mathrm{e}, \mathrm{f}}$ & $34.48 \pm 4.16^{\mathrm{A}, \mathrm{d}}$ \\
\hline $\mathrm{Sb}$ & S. boulardii & $16.22 \pm 3.50^{\mathrm{a}}$ & $25.50 \pm 5.81^{\mathrm{A}, \mathrm{f}}$ & $34.75 \pm 2.95^{\mathrm{A}, \mathrm{d}, \mathrm{e}, \mathrm{f}}$ & $77.05 \pm 5.74^{\mathrm{B}, \mathrm{c}}$ \\
\hline
\end{tabular}

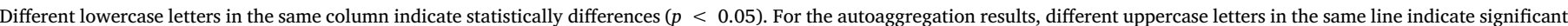
differences $(p<0.05)$ by Tukey's test. ND - not determined.

observed in these strains could be related to the ability of yeasts that can produce and deliver a substance of proteinaceous nature known as mycocin or killer toxin, which is lethal for sensitive yeasts of the same species or of other genera (Banjara, Nickerson, Suhr, \& Hallen-Adams, 2016; Gil-Rodríguez et al., 2015).

Concerning the probiotic reference strain ( $S$. boulardii), it has not been demonstrated antimicrobial activity against the tested pathogens. Nevertheless, Czerucka, Piche, and Rampal (2007) observed antimicrobial effect of this yeast for various enteric pathogens such as Clostridium difficile, Vibrio cholerae, Salmonella, Shigella and E. coli.

\subsection{Principal Component Analysis (PCA)}

Principal Component Analysis (PCA) was used in order to analyze simultaneously all the relevant variables. The variables used corresponded to the results of protease (Prot), $\beta$-glucosidase (B-gluc), xylanase (Xil), lipase (Lip), antimicrobial activity (AM), antioxidant activity (AA), autoaggregation (Ag2h, Ag4h and Ag24h), survival of gastric (SG) and pancreatic (SP) digestions, and total survival (ST).

The biplot of the principal components (Fig. 1) showed the existence of two major factors that explained $54.21 \%$ of the total variance of the original variables (34.29\% for Factor 1 and 19.92\% for Factor 2). The first component was mainly related to lipase, antioxidant activity, autoaggregation at 2, 4 and $24 \mathrm{~h}$, gastric survival, and total survival. The second component (Factor 2 ) was mainly related to xylanase, $\beta$-glucosidase, antimicrobial activity and pancreatic survival (Fig. 1). The assayed yeast strains could be classified into four different groups. The first group included the strain $C$. norvegica 7A which showed the highest antimicrobial activity. The second group included the strain $P$. guilliermondii 25A, which presented the highest total survival. The third group included the strains $D$. hansenii 8A, C. boidinii 37A and C. tropicalis 3A. D. hansenii 8A was the one with the lowest values for the antioxidant activity and autoaggregation ability, while $C$. tropicalis $3 \mathrm{~A}$ showed the highest survival to gastric digestion. The remaining strains were included in the fourth group.

\section{Conclusions}

In this study we isolated yeast strains that could be used as new probiotic strains. S. cerevisiae showed lipase activity, high ability to grow at the host temperature and high antioxidant capacity, $S$. cerevisiae $15 \mathrm{~A}$ showed higher autoaggregation percentage than the reference

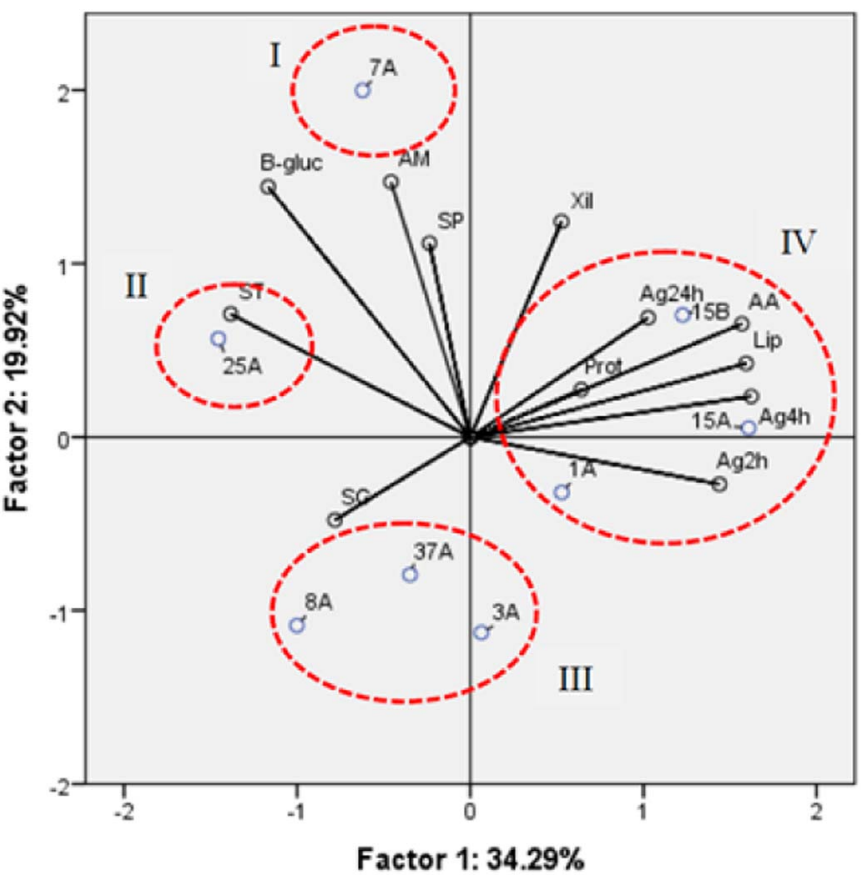

Fig. 1. Loadings and scores plot resulting from the Principal Component Analysis applied to the yeast strains, considering the following variables: AA: antioxidant activity; $\mathrm{Ag} 2 \mathrm{~h}$, $\mathrm{Ag} 4 \mathrm{~h}$ and Ag24h: autoaggregation at 2, 4 and $24 \mathrm{~h}$, respectively; Survival of gastric (SG), pancreatic (SP), and total digestions (ST); Prot: protease; Xil: xylanase; B-gluc: $\beta$-glucosidase; AM: amylase; and Lip: lipase.

strain. $P$. guilliermondii and $C$. norvegica exhibited ability to survive to the human gastrointestinal tract digestion. Our results also demonstrated that $C$. norvegica have antimicrobial activity against $C$. neoformans. Nevertheless, it would be interesting to perform additional tests to these strains to better understand the mechanisms involved, taking into account their role in table olives fermentation and table olives characteristics, as well as to evaluate other probiotic properties, including hydrophobicity, antibiotic resistance, and adhesiveness to Caco-2 enterocytes. Furthermore, in vivo testing using animal models should be developed in order to ascertain the benefits observed in vitro. 


\section{References}

Abbas, C. A. (2006). Production of antioxidants, aromas, colours, flavours and vitamins by yeasts. In A. Querol, \& G. Fleet (Eds.), Yeasts in food and beverages (pp. 285-334). Berlim Heidelberg: Springer-Verlag. http://dx.doi.org/10.1007/978-3-540-28398010.

Argyri, A. A., Zoumpopoulou, G., Karatzas, K. G., Tsakalidou, E., Nychas, G. E., Panagou, E. Z., \& Tassou, C. C. (2013). Selection of potential probiotic lactic acid bacteria from fermented olives by in vitro tests. Food Microbiology, 33, 282-291. http://dx.doi.org/ 10.1016/j.fm.2012.10.005

Arroyo-López, F. N., Romero-Gil, V., Bautista-Gallego, J., Rodríguez-Gómez, F., JiménezDíaz, R., García-García, P., ... Garrido-Fernández, A. (2012). Yeasts in table olive processing: Desirable or spoilage microorganisms? International Journal of Food Microbiology, 160(1), 42-49. http://dx.doi.org/10.1016/j.ijfoodmicro.2012.08.003.

Banjara, N., Nickerson, K. W., Suhr, M. J., \& Hallen-Adams, H. E. (2016). Killer toxin from several food-derived Debaryomyces hansenii strains effective against pathogenic Candida yeasts. International Journal of Food Microbiology, 222, 23-29. http://dx.doi. org/10.1016/j.ijfoodmicro.2016.01.016.

Bautista-Gallego, J., Arroyo-López, F. N., Rantsiou, K., Jiménez-Díaz, R., GarridoFernández, A., \& Cocolin, L. (2013). Screening of lactic acid bacteria isolated from fermented table olives with probiotic potential. Food Research International, 50(1), 135-142. http://dx.doi.org/10.1016/j.foodres.2012.10.004.

Bautista-Gallego, J., Rodríguez-Gómez, F., Barrio, E., Querol, A., Garrido-Fernández, A., \& Arroyo-Lopez, F. N. (2011). Exploring the yeast biodiversity of green table olive industrial fermentations for technological applications. International Journal of Food Microbiology, 147(2), 89-96. http://dx.doi.org/10.1016/j.ijfoodmicro.2011.03.013.

Bonatsou, S., Benítez, A., Rodríguez-Gómez, F., Panagou, E. Z., \& Arroyo-López, F. N. (2015). Selection of yeasts with multifunctional features for application as starters in natural black table olive processing. Food Microbiology, 46, 66-73. http://dx.doi.org/ 10.1016/j.fm.2014.07.011

Chen, L.-S., Ma, Y., Maubois, J.-L., Chen, L.-J., Liu, Q.-H., \& Guo, J.-P. (2010). Identification of yeasts from raw milk and selection for some specific antioxidant properties. International Journal of Dairy Technology, 63(1), 47-54. http://dx.doi.org/ 10.1111/j.1471-0307.2009.00548.x.

Czerucka, D., Piche, T., \& Rampal, P. (2007). Review article: Yeast as probiotics Saccharomyces boulardii. Alimentary Pharmacology \& Therapeutics, 26, 767-778. http://dx.doi.org/10.1111/j.1365-2036.2007.03442.x.

FAO/WHO (2006). Probiotics in food: Health and nutritional properties and guidelines for evaluation. FAO food nutrition pap. 85. Rome: World Health Organization and Food and Agriculture Organization of the United Nations.

García-Cayuela, T., Korany, A. M., Bustos, I., Gomez de Cadiñanos, L. P., Requena, T., Peláez, C., \& Martínez-Cuesta, M. C. (2014). Adhesion abilities of dairy Lactobacillus plantarum strains showing an aggregation phenotype. Food Research International, 57, 44-50. http://dx.doi.org/10.1016/j.foodres.2014.01.010.

Gil-Rodríguez, A. M., Carrascosa, A. V., \& Requena, T. (2015). Yeasts in foods and beverages: In vitro characterisation of probiotic traits. LWT - Food Science and Technology, 64(2), 1156-1162. http://dx.doi.org/10.1016/j.lwt.2015.07.042.

Hernández, A., Martín, A., Aranda, E., Pérez-Nevado, F., \& Córdoba, M. G. (2007) Identification and characterization of yeast isolated from the elaboration of seasoned green table olives. Food Microbiology, 24, 346-351. http://dx.doi.org/10.1016/j.fm. 2006.07.022.

Jaehrig, S. C., Rohn, S., Kroh, L. W., Fleischer, L. G., \& Kurz, T. (2007). In vitro potential antioxidant activity of $(1 \rightarrow 3),(1 \rightarrow 6)$-beta-D-glucan and protein fractions from Saccharomyces cerevisiae cell walls. Journal of Agricultural and Food Chemistry, 55 , 4710-4716. http://dx.doi.org/10.1021/jf063209q.

Lukaszewicz, M. (2012). Saccharomyces cerevisiae var. boulardii - Probiotic yeast. In E. C. Rigobelo (Ed.), Probiotics (pp. 385-398). Rijeka: InTech. http://dx.doi.org/10.5772/ 50105.

Moslehi-Jenabian, S., Pedersen, L. L., \& Jespersen, L. (2010). Beneficial effects of probiotic and food borne yeasts on human health. Nutrients, 2, 449-473. http://dx. doi.org/10.3390/nu2040449.

Motta, V. T. (2000). Bioquímica clínica: princípios e interpretações. EditoraMédica Massau. Mumy, K. L., Chen, X. H., Kelly, C. P., \& McCormick, B. A. (2008). Saccharomyces boulardi interferes with Shigella pathogenesis by postinvasion signaling events. American Journal of Physiology - Gastrointestinal and Liver Physiology, 294, G599-G609. http:// dx.doi.org/10.1152/ajpgi.00391.2007.

Pereira, E. L., Ramalhosa, E., Borges, A., Pereira, J. A., \& Baptista, P. (2015). Yeast dynamics during the natural fermentation process of table olives (Negrinha de Freixo cv.). Food Microbiology, 46, 582-586. http://dx.doi.org/10.1016/j.fm.2014.10.003.

Peres, C. M., Peres, C., Hernández-Mendoza, A., \& Malcata, F. X. (2012). Review on fermented plant materials as carriers and sources of potentially probiotic lactic acid bacteria - With an emphasis on table olives. Trends in Food Science \& Technology, 26, 31-42. http://dx.doi.org/10.1016/j.tifs. 2012.01.006.

Perricone, M., Bevilacqua, A., Corbo, M. R., \& Sinigaglia, M. (2014). Technological characterization and probiotic traits of yeasts isolated from Altamura sourdough to select promising microorganisms as functional starter cultures for cereal-based products. Food Microbiology, 38, 26-35. http://dx.doi.org/10.1016/j.fm.2013.08.006.

Pessione, A., Bianco, G. L., Mangiapane, E., Cirrincione, S., \& Pessione, E. (2015). Characterization of potentially probiotic lactic acid bacteria isolated from olives: Evaluation of short chain fatty acids production and analysis of the extracellular proteome. Food Research International, 67, 247-254. http://dx.doi.org/10.1016/j. foodres.2014.11.029.

Ragon, M., Aumelas, A., Chemardin, P., Galvez, S., Moulin, G., \& Boze, H. (2008). Complete hydrolysis of myo-inositol hexakisphosphate by a novel phytase from Debaryomyces castellii CBS 2923. Applied Microbiology and Biotechnology, 78, 47-53. http://dx.doi.org/10.1007/s00253-007-1275-3.

Rodríguez-Gómez, F., Romero-Gil, V., García-García, P., Garrido-Fernández, A., \& ArroyoLópez, F. N. (2014). Fortification of table olive packing with the potential probiotic bacteria Lactobacillus pentosus TOMC-LAB2. Frontiers in Microbiology, 5, 1-9. September http://dx.doi.org/10.3389/fmicb.2014.00467.

Ruiz-Moyano, S., Martín, A., Benito, M. J., Nevado, F. P., \& Córdoba, M. D. G. (2008) Screening of lactic acid bacteria and bifidobacteria for potential probiotic use in Iberian dry fermented sausages. Meat Science, 80, 715-721. http://dx.doi.org/10. 1016/j.meatsci.2008.03.011.

Samad, M., Razak, C., Salleh, A., Yunus, W. M. Z. W., Ampon, K., \& Basri, M. (1989). A plate assay for primary screening of lipase activity. Journal of Microbiological Methods, 9, 51-56. http://dx.doi.org/10.1016/0167-7012(89)90030-4.

Silva, T., Reto, M., Sol, M., Peito, A., Peres, C. M., Peres, C., \& Malcata, F. X. (2011). Characterization of yeasts from Portuguese brined olives, with a focus on their potentially probiotic behavior. LWT - Food Science and Technology, 44, 1349-1354. http://dx.doi.org/10.1016/j.lwt.2011.01.029.

Sourabh, A., Kanwar, S. S., \& Sharma, O. P. (2011). Screening of indigenous yeast isolates obtained from traditional fermented foods of Western Himalayas for probiotic attributes. Journal of Yeast and Fungal Research, 2(8), 117-126. http://www. academicjournals.org/JYFR.

Strauss, M. L. A., Jolly, N. P., Lambrechts, M. G., \& Rensburg, P. V. (2001). Screening for the production of extracellular hydrolytic enzymes by non-Saccharomyces wine yeasts. Journal of Applied Microbiology, 91, 182-190. http://dx.doi.org/10.1046/j. 1365-2672.2001.01379.x.

Syal, P., \& Vohra, A. (2013). Probiotic potential of yeasts from traditional Indian fermented foods. International Journal of Microbiology Research, 5(2), 390-398. http:// dx.doi.org/10.9735/0975-5276.5.2.390-398.

Vidon, N., Huchet, B., \& Rambaud, J. C. (1986). Influence de "Saccharomyces boulardii" sur la sécrétion jéjunale induite chez le rat par la toxine cholérique. Gastroenterologie Clinique et Biologie, 10, 13-16.

Whittenbury, R. (1964). Hydrogen peroxide formation and catalase activity in the lactic acid bacteria. Journal of General Microbiology, 35, 13-26. http://dx.doi.org/10.1099/ 00221287-35-1-13. 